\title{
Escolas paulistas ocupadas, políticas e democracias
}

\author{
Occupied schools in sao paulo, policies and democracies \\ Escuelas paulistas ocupadas, políticas y democracias
}

\author{
GRAZIELA ZAMBÃO ABDIAN \\ https://orcid.org/0000-0001-5698-000X \\ Universidade Estadual Paulista Júlio de Mesquita Filho \\ Programa de Pós-graduação em Educação \\ Marília, SP, Brasil \\ VIVIANE IZAÍAS DE CARVALHO \\ https://orcid.org/0000-0001-9843-0006 \\ Universidade Estadual Paulista Júlio de Mesquita Filho \\ Programa de Pós-graduação em Educação \\ Marília, SP, Brasil \\ VIVIANI FERNANDA HOJAS \\ https://orcid.org/0000-0002-9841-0301 \\ Universidade Federal do Acre \\ Programa de Pós-graduação em Educação \\ Rio Branco, AC, Brasil
}

\begin{abstract}
Resumo: O objetivo foi analisar as práticas discursivas construídas sobre política, gestão e democracia por diferentes integrantes de duas escolas públicas da rede estadual paulista ocupadas em 2015/2016 contra a política governamental de reorganização escolar. O material é resultante de entrevistas com integrantes de diferentes segmentos das duas escolas pesquisadas, analisadas a partir do referencial teórico da teoria do discurso. A experiência nas ocupações teve grande importância na ressignificação da escola e das categorias em tela e a teoria do discurso pôde contribuir com o avanço no conhecimento da área.
\end{abstract}

Palavras-chave: Escolas paulistas ocupadas. Políticas e democracias. Teoria do discurso. Gestão escolar.

\begin{abstract}
The purpose was to analyze the discursive practices built on policies, management and democracy by different members of two public schools in São Paulo state network occupied in 2015/2016 against the government policy of school reorganization. The material is the result of interviews with members of different segments of the two schools surveyed and the theoretical reference the Discourse Theory. The experience in the occupancy had great importance in the reframing of the school and the categories onscreen and the Discourse Theory could contribute to the advance in the Knowledge of the area.
\end{abstract}

Keywords: Occupied Schools in Sao Paulo. Politics and Democracies. Discourse Theory. School management. 
Resumen: El objetivo ha sido analizar las prácticas discursivas construidas sobre politica, gestión y democracia por diferentes integrantes de dos escuelas públicas estaduales paulistas ocupadas en 2015/2016 contra la política gubernamental de reorganización escolar. El material es el resultado de entrevistas con integrantes de diferentes segmentos de dos escuelas investigadas y el referencial teórico es la Teoría del Discurso. La experiencia en las ocupaciones ha tenido gran importancia en la resignificación de la escuela y de las referidas categorías abordadas y la Teoría del Discurso ha podido contribuir con el avance en el reconocimiento del área.

Palabras clave: Escuelas paulistas ocupadas. Politicas y Democracias. Teoría del Discurso.

\section{INTRODUÇÃO}

Este artigo é parte de pesquisa integrada, cujo objetivo geral é analisar a (re)configuração da área da Administração Educacional/Escolar no Brasil, após período crítico dos anos 1980, cotejando o desenvolvimento teórico e os desdobramentos práticos na gestão dos sistemas e unidades escolares. Baseamonos em algumas constatações que justificam sua realização: o campo teórico da educação, em especial da política e gestão da educação, não tem privilegiado as práticas discursivas dos estudantes, funcionários e responsáveis; as análises são prescritivas, fato que será fundamentado com base nos argumentos de um conjunto de autores (SOUZA, 2006; MAIA, 2008; MURCIA, 2015; RUSSO; MAIA, 2009).

Souza (2006) traçou o perfil da gestão escolar no Brasil e realizou levantamento e análise das pesquisas dos Programas de Pós-Graduação em Educação do país (1987-2004). O autor destaca que a produção científica teve como tendência a compreensão da gestão escolar como fenômeno preponderantemente político, com significativa ampliação das temáticas contempladas. Do total de 514 pesquisas, 150 dizem respeito à gestão democrática e/ou participação na escola; e aproximadamente 27 se caracterizam por aprofundarem a discussão conceitual do campo. O maior problema da produção refere-se à "[...] ênfase por vezes um tanto normativa de vários trabalhos sobre gestão escolar" que se "[...] dedicam mais a demonstrar como a escola deve se organizar para ser democrática e menos a descrever e analisar como tem se organizado a gestão da escola, democrática ou não." (SOUZA, 2006, p. 122).

Maia (2008) analisou a produção da Revista Brasileira de Política e Administração da Educação (RBPAE), entre 1983-2005 e, no que tange às categorias "administração" e "gestão", constatou a contribuição desta publicação para a área, na medida em que foi detectável o abandono de teorias generalizáveis construídas com base na administração empresarial; também percebeu haver preferência por estudos que analisavam as escolas, aproximando os pesquisadores 
de seu objeto analisado. Assim como essa autora, Russo e Maia (2009) concluíram que houve proliferação de estudos sobre o cotidiano escolar, ao realizarem levantamento, sistematização e análise de livros publicados em primeira edição, que trazem a escola como objeto de estudo para identificar suas contribuições a partir da delimitação de seus referenciais teórico-metodológicos. As autoras destacaram a predominância de pesquisas e análises que partem da gestão democrática ou da imagem da escola democrática (COSTA, 2003), mas que a constroem como um ideal a ser vivenciado nas realidades escolares. Ou seja, o conhecimento produzido nas produções acadêmicas evidencia a inexistência da escola democrática na realidade do campo empírico.

Murcia (2015) realizou levantamento, sistematização e análise dos artigos publicados na RBPAE (2000-2010) que tratam especificamente da gestão democrática. Suas considerações não ao encontro do que trazem os autores anteriormente analisados no que diz respeito, especificamente, ao não rompimento com a construção de teorias prescritivas. $\mathrm{O}$ autor destaca que há predominância de artigos que coletam dados empíricos de realidades específicas, mas que apresentam tendências a conclusões semelhantes: há mais limites para a gestão democrática ser efetiva do que possibilidades, ou seja, a teoria que levam para a realidade encontra limites na própria realidade. Ele identificou que os estudos discutem a temática, tendo como horizonte a vivência da gestão democrática garantida na legislação nacional vigente.

Esse conjunto de constatações nos impõe movimentos necessários na área em que pretendemos contribuir com a produção deste artigo, qual seja: a busca de novos horizontes implicados na relação teoria e prática, em que uma não seja predominante em relação à outra, melhor dizendo, uma não diga o que a outra deve fazer.

Tendo como contexto a pesquisa integrada e o conjunto de constatações e desafios apontados, apresentamos como questão norteadora: quais são os sentidos construídos sobre gestão democrática por diferentes integrantes da escola pública estadual paulista, ocupadas em 2015/2016 contra a reorganização escolar? (CARVALHO, 2020). Portanto, analisamos as práticas discursivas de diferentes integrantes dessas escolas sobre política, democracia e gestão, com respaldo da teoria do discurso (LACLAU; MOUFEE, 2015).

Em busca sistemática no banco de teses da Coordenação de Aperfeiçoamento de Pessoal de Nível Superior (Capes), encontramos 16 trabalhos com a mesma temática e/ou referencial. Do total, 10 são da área de currículo. Entre os demais, merecem destaque os estudos de Marques (2011) e Oliveira, Oliveira e Martins (2013). No entanto, nenhum analisou a política e a gestão das escolas paulistas ocupadas. O contexto político nacional e estadual também 
justifica a importância de nossa temática, pois nele se constituíram movimentos sociais reivindicando direitos e lutando contra a opressão. Para nós, é importante "[...] identificar as condições discursivas de emergência de uma ação coletiva que objetive a lutar contra desigualdades e a questionar relações de subordinação." (LACLAU; MOUFFE, 2015, p. 248). Ou seja, analisar as práticas discursivas dos integrantes das escolas em um momento de forte resistência pode ser algo diferenciado nas pesquisas que mostram não haver gestão democrática escolas públicas e, por tal razão, prescrevem o que deve ser feito para isso.

O campo de pesquisa são duas escolas públicas da rede estadual paulista, ocupadas contra a política governamental de reorganização escolar ${ }^{1}$. Inicialmente, tínhamos o intuito de entrevistar dois integrantes de cada segmento das escolas (gestores, professores, funcionários, pais ou responsáveis e alunos). Contudo, durante a realização dessa etapa da pesquisa, tivemos dificuldades em localizar tais integrantes. Sendo assim, realizamos um total de 14 entrevistas, com: um gestor(a) de cada escola; quatro professores(as) em uma escola e dois em outra; quatro alunos(as) em uma escola e apenas um em outra; e uma funcionária da segunda escola. As entrevistas foram de tipo semiestruturadas e desenvolvidas a partir de um esquema básico, mas que pôde ser adaptado de acordo com as necessidades que surgiram no contexto da conversa. No esquema, privilegiamos os seguintes aspectos: a) tempo de trabalho na escola (ou tempo de estudante ou de responsável por estudante) e em que momento - antes, depois ou durante a ocupação; b) para os profissionais, especificamente: formação; c) o que mais gosta da profissão ou da escola; d) principais dificuldades; e) como concebe a gestão da escola, quais as maiores dificuldades, quais suas potencialidades; f) como compreende a política e onde se faz política; g) qual (ou quais) a relação da política com a escola e com a gestão; h) quais são suas potencialidades e dificuldades; i) como compreende a democracia, relações com a escola, com a gestão, limites e potencialidades; j) participou das ocupações, por que, como tudo começou, sua vivência no movimento; k) maiores potencialidades e dificuldades das ocupações.

A resposta à questão lançada no início desta introdução foi construída em três partes que se seguem: primeiro, desenvolveremos as categorias principais que nortearam nossa análise - políticas e democracias, as quais são contempladas pela teoria do discurso (LACLAU; MOUFFE, 2015), bem como a categoria que nos constitui como pesquisadores - gestão; na sequência, traremos as práticas discursivas dos integrantes das duas escolas paulistas ocupadas; e finalizaremos com as considerações finais.

\footnotetext{
1 Movimento iniciado pelos estudantes, em diferentes cidades do estado, manifestando-se contrariamente à proposta de reorganizar as escolas, cujos desdobramentos incidiriam em transferências de professores de escolas e fechamentos de salas de aulas.
}

1074 - Rev. Bras. Polít. Adm. Educ. - v. 37, n. 2, p. 1071 - 1091, mai./ago. 2021 
É preciso destacar que, com Laclau e Mouffe (2015, p. 181), compreendemos a estrutura discursiva como uma prática articulatória que constitui e organiza as relações sociais, ou seja, o discurso, por constituir as relações sociais, não permite a distinção do "discurso" e do "não discurso" (ou separação entre pensamento e realidade), uma vez que o objeto é construído a partir de uma prática discursiva. O objeto "democracia", portanto, constitui-se dentro de uma "condição discursiva" que apresenta um "caráter material". Desta forma, analisar as práticas discursivas dos integrantes que compõem a escola passa a ter um significado especial na compreensão da escola como princípio educativo de pesquisa (ABDIAN, 2020).

\section{ESCOLA COMO PRINCÍPIO DE PESQUISA: POLÍTICAS, DEMOCRACIAS E GESTÃO COMO CATEGORIAS ANALÍTICAS}

Perspectivando o cotidiano como princípio de pesquisa na área da educação, entendemos que não se trata apenas de um novo item na agenda dos pesquisadores, mas uma forma diferente de compreensão das problemáticas que estão presentes na escola, e mais, não se pode correr o risco “[...] de retirar a ênfase de uma instância (política) e a ter colocado em outra instância (cotidiano) e não ter abandonado a prática de pesquisar com duas instâncias em que uma seja desvalorizada para a outra se construir." (ABDIAN, 2020, p. 12). A ideia que nos subsidia é, portanto, aquela defendida por Gallo e Figueiredo (2015), de que analisar a escola, em seu cotidiano, é um modo menor de fazer pesquisa, buscando suas "linhas de fuga" e sua potência de criação. Essa construção filosófica é condizente com a análise política que fazemos das categorias que nortearam o estudo: políticas, democracias e gestão.

Amparados por Mouffe (2011), entendemos que a política não é um produto construído, consumido ou implementado pela escola, ela é constituída por sentidos políticos de formação da própria humanidade. Dessa forma, compreender os estudos da gestão como um braço da política, como nas perspectivas apresentadas, pode fragilizar a gestão escolar ao desconsiderar sua potencialidade em produzir política na própria escola. Concordando com a autora, distinguimos "o político" e "a política", da seguinte forma:

[...] por "o político" a dimensão de antagonismo que considero constitutiva das sociedades humanas, enquanto entendo por "política" o conjunto de práticas e instituições por meio das quais uma ordem é criada, organizando a coexistência humana no contexto conflituoso produzido pelo político. (MOUFFE, 2011, p. 8). 
"A política" pode ser entendida como instituições ou organizações sistematizadas de representatividade, como os partidos políticos, as igrejas e as escolas. Como uma atividade que organiza a vida das pessoas, articulada aos processos de construção de identidades coletivas, marcada por paixões e negociações. O sentido do "político" se articula à produção dessas políticas, é "[...] uma ação ontológica do conhecimento da própria ação como homem e mulher." (ABDIAN; ANDRADE; PARRO, 2017, p. 738), inerente a toda e qualquer pessoa. É nesse último que são formadas as relações sociais e onde elas são simbolicamente ordenadas, com conflitos nos quais o antagonismo tem importância fundamental.

Para Mouffe (2011), esse terreno antagônico da constituição de políticas é necessário, pois nos constituímos na e com a presença do outro. Mas esse outro pode ser destruído na luta entre inimigos, eliminando as necessárias e múltiplas negociações do jogo político. Por isso, a autora nos propõe um deslocamento para o terreno agônico, onde não há destruição, mas uma luta entre adversários pela hegemonização de determinado projeto político.

Assumimos a posição de pensar nas produções de políticas de gestão a partir da categoria adversário, da mudança do antagonismo para o agonismo, pois isso significa ir além de uma visão consensual, em que os governos produzem e as escolas reproduzem ou são infiéis. As discussões e os embates não devem ser vistos como negativos ou apagados, pois proporcionam possibilidades de avanços na constituição de políticas, tornando-se um espaço onde múltiplas vozes podem ser ouvidas.

Todo esse movimento é importante, pois alimenta e serve como propulsor para o processo democrático, como o entendemos. É “[...] no cotidiano escolar e também nos governos [que] há um fluxo contínuo de produção de política de gestão que negociam seus sentidos para efetivação do que acreditam serem as melhores estratégias para uma educação de qualidade." (ABDIAN; ANDRADE; PARRO, 2017, p. 740). O processo democrático depende dessas hegemonizações parciais e provisórias, por isso, para a construção da hegemonia e do discurso, a prática articulatória aparece como algo importante. Mas “[...] para nos posicionarmos firmemente no campo da articulação, devemos começar renunciando à concepção de 'sociedade' como totalidade fundante de seus processos parciais.” (LACLAU; MOUFFE, 2015, p. 166). Dessa forma, a noção de sociedade se torna impossível no seu sentido pleno, pois os sentidos sociais são sempre incompletos e não há a real possibilidade de se chegar ao "fim da história", uma vez que os sentidos são precários e estão permeados por inconstâncias, e mesmo que um discurso se constitua como hegemônico, ele não o será por muito tempo ou, ainda, nas palavras de Laclau e Mouffe (2015, p. 166), essas 
tentativas de busca por uma essência são "tentativas fracassadas de domesticar o campo das diferenças." E quanto maior a emergência dessas diferenças, maior a possibilidade de identificações e, consequentemente, equivalências. E é aqui que os autores mostram a importância de uma estrutura discursiva, que é uma prática articulatória que constitui e organiza as relações sociais.

Com isso, a defesa da escola democrática no âmbito acadêmico deveria enfrentar o desafio desse reconhecimento do pluralismo de valores, deixando de lado as formas de escapismo, pois, segundo Mouffe (2011, p. 18): "Indivíduos da democracia só serão possíveis com a multiplicação de instituições, discursos, formas de vida que fomentem a identificação com valores democráticos."

É nessa perspectiva do cotidiano como princípio de pesquisa e de política de gestão e democracia como campo de negociação de sentidos e de hegemonização que analisamos as falas dos integrantes das escolas paulistas ocupadas.

Compreender democracia dessa forma pode nos possibilitar analisar as relações sociais na pluralidade mesma em que ela se manifesta. $\mathrm{Na}$ escola, exatamente pela pluralidade de sujeitos envolvidos e de vivências, não poderia ser diferente. Por isso, a partir desse estudo e dos apontamentos dos autores, não é possível mais compreender a escola como uma coisa uniforme, como é forçada a ser nas pesquisas, principalmente em se tratando de democracia. Compreender e trabalhar essa pluralidade são desafios que nos propomos e apresentamos, pois nos permitem ampliar o campo teórico-metodológico da área e também investigála de forma diferente e com mais possibilidades, pois, assim como Laclau (2011, p. 150) afirma, uma sociedade democrática “[...] não é aquela em que o 'melhor' conteúdo domina sem contestação, mas aquela em que nada é alcançado de uma vez por todas e há sempre a possibilidade de questionamento.”

\section{PRÁTICAS DISCURSIVAS DOS INTEGRANTES DAS ESCOLAS SOBRE POLÍTICAS, DEMOCRACIAS E GESTÃO}

Conforme explicitado na seção anterior, entendemos que a política não é um produto vindo dos órgãos de governo (federal, estadual ou municipal) para ser implementada e/ou consumida pelos integrantes das escolas, mas algo produzido e articulado pelo "político". As relações sociais na escola acontecem na dimensão do antagonismo - do político - e o contexto de conflitualidade que organiza a vida das pessoas produz a política. Assim, compreendemos a escola e seus integrantes como uma dimensão da política, constituindo-a por meio do político. 
E quais são os sentidos sobre a política presentes na prática discursiva dos integrantes das escolas pesquisadas? ${ }^{2}$ ?

Os professores entrevistados afirmam que a política está mais associada às relações sociais multiplicadas e ao poder, em sentidos diversos. "Política é o poder (força) social (diante dos demais) que todos têm (ou deveriam ter) diante das decisões que envolvem a vida pública.” (PROFESSORA 1.3, 2019); “[...] abrange muita coisa né, não é algo restrito, é tudo que é feito em conjunto pra um bem comum, que considera as necessidades não só de uma pessoa, mas de uma comunidade." (PROFESSORA 2.4, 2019); “[...] a política faz parte da essência do ser enquanto um ser social, então a todo o momento, enquanto eu me relaciono com as pessoas, eu estou estabelecendo relações políticas, genéricas, mas ainda assim, políticas." (PROFESSOR 1.4, 2019). Além de ser "[...] a correlação de forças no poder." (PROFESSORA 1.1, 2019), ela é vista como “[...] relações de poder, então onde existe relação de duas ou mais pessoas você tem uma relação política." (PROFESSORA 1.2, 2019).

Para os docentes das duas escolas pesquisadas, então, a política não se restringe ao âmbito das decisões governamentais, pois ela é constitutiva das relações sociais e das decisões que envolvem o público (a vida pública).

Pela vivência ativa nas ocupações, os alunos consideram que "[...] a política entrou exatamente nesse meio, de eu levar a voz da população, da comunidade acadêmica." (ALUNO 1.1, 2019); além disso, ela é "[...] a organização basicamente, de um país, de uma cidade, de um Estado, visando os interesses da população, que é o que deveria ser feito né, nem sempre é feito dessa forma, na verdade o contrário." (ALUNO 1.3, 2019).

As potencialidades da política estão basicamente relacionadas ao povo, pois "[...] é a unificação do povo em prol de garantias sociais, sejam elas bens comum, Educação, Seguridade Social e Segurança.” (ALUNO 1.1, 2019), mas isso só é possível "[...] se houvesse um trabalho [...] mais em conjunto." (ALUNA 1.2, 2019), pois "[...] você tem que respeitar a opinião dos outros, independente do que ele pensa ou não e tentar, em conjunto, tá resolvendo os problemas, fazendo o que é melhor." (GESTORA 2.1, 2019).

A noção de coletividade parece ter sido ressignificada nas ocupações, pois os professores indicam que a maior potencialidade da política é "[...] construir essa ação com a ideia de coletividade, se sentir pertencente e agindo nos espaços

2 Nomeamos as escolas pesquisadas como Escola 1 e Escola 2. Os professores da Escola 1 de Professor 1.1, Professor 1.2, e assim sucessivamente com os demais segmentos de ambas as escolas para mantermos o anonimato e o sigilo. 
em que você vive.” (PROFESSOR 1.4, 2019); e não apenas agir nesses espaços; é também "[...] a construção social desses espaços, uma construção de uma política democrática, de uma relação democrática.” (PROFESSOR 2.3, 2019).

Os aspectos relacionados ao poder estiveram muito presentes e marcantes nas falas dos professores e alunos das duas escolas ao afirmarem que as políticas "[...] estão relacionadas ao poder de transformação social, ao trabalho pra melhorar, dar qualidade de vida, melhorar a condição de vida das pessoas." (PROFESSORA 2.4, 2019); ao "[...] poder [...] pra fazer as coisas" (ALUNA 2.1, 2019). Segundo uma docente:

[...] se a gente tem a política como relação de poder e o conhecimento como poder, conhecimento é [...] um dos itens que se confere poder na sociedade, você tem um espaço por excelência político né, e o que potencializa ainda mais isso é o fato de ser uma escola pública né, de não ter uma dívida com uma visão privada, de não ter uma obrigatoriedade de defender uma ideologia específica, de ser devota da liberdade de expressão, o espaço que deve ser essencial, um espaço público por essencial onde ocorra a liberdade de expressão. (PROFESSORA $1.2,2019)$.

Além de destacarem a política como relações sociais e poder coletivo, professores e alunos indicam a necessidade de ação humana, pois o "bem comum" se constitui, "[...] principalmente, pressionando né, essa é nossa função dentro desse meio político." (PROFESSORA 1.1, 2019). Assim, “[...] se for bem usada, ela consegue melhorar bastante a situação geral de qualquer lugar que você esteja, seja desde uma escola, até um país." (ALUNO 1.3, 2019).

Os sentidos da política como relações sociais multiplicadas e poder coletivo são ainda mais evidenciados pelos professores quando contemplam as dificuldades que a envolvem. As principais dificuldades da política estão ligadas a “[...] essa falsa compreensão, essa compreensão errada de que ela está relacionada apenas ao Congresso, ao Senado e ao voto representativo, porque eu acredito que política, na verdade, se faz com participação, não com representação." (PROFESSORA 1.1, 2019); para outra docente, seria importante "[...] o reconhecimento de que há política em todas as ações; a repressão dos pobres, que reagem politicamente todos os dias ao sobreviver aos mandos e desmandos dos que tomam a maior parte do espaço de decisão.” (PROFESSORA 1.3, 2019).

Já os maiores desafios relacionados à política, segundo os docentes, são: "[...] se sentir pertencente e conseguir agir de forma consciente em todos os espaços que você está.” (PROFESSOR 1.4, 2019); fazer as pessoas entenderem e verem "[...] a importância dessa construção e quanto isso atinge a sociedade, [...] pra ser mais específica eu acho que o desafio é fazer com que as pessoas acreditem que existe liberdade de expressão." (PROFESSORA 1.2, 2019). 
No sentido convergente, para os alunos, algumas dificuldades estão ligadas ao individualismo, como "Não ouvir o outro, [...] atender as necessidades do outro, só se preocupar com o seu, com si próprio.” (ALUNA 1.2, 2019); pois "[...] a dificuldade deles [governo paulista] é não pensar na gente." (ALUNA 2.1, 2019).

Um dos professores e a gestora da Escola 2 também indicam o individualismo como algo que dificulta a vivência política: “[...] as dificuldades estão relacionadas ao uso da política para a defesa de interesses individuais e não para o bem de uma comunidade, o bem da maioria das pessoas." (PROFESSORA 2.4, 2019); “[...] é quando as pessoas não respeitam as opiniões.” (GESTORA 2.1, 2019).

Um dos alunos relaciona a política com a gestão, dizendo que a maior dificuldade nos dois casos é "[...] lidar com muitas pessoas, com muitas opiniões diferentes, é difícil agradar todo mundo e é fácil fazer todo mundo ficar irritado com você." (ALUNO 1.3, 2019). Essa opinião se associa à vivência dos alunos nas ocupações. Um deles relata que as três maiores dificuldades da política são:

$1^{\circ}$ ) engajamento da comunidade como um todo, durante o período de ocupações, os diálogos com o governo foram longos, durando quase três semanas e a maioria das pessoas não estão em posição de se dedicarem exclusivamente ao movimento como atividade primária. $2^{\circ}$ ) Desinformação, parte significativa da população não tem conhecimento sobre seus próprios direitos e deveres, e o trabalho de base infelizmente não atinge imediatamente essas pessoas. $3^{\circ}$ ) Indústria do medo, as mídias acabam retratando de forma pejorativa ou sensacionalista determinadas situações que atingem a população de forma negativa, os deixando receosos ou acuados, isso atribui com a não participação de algumas pessoas. (ALUNO 1.1, 2019).

Quando questionados sobre o lugar onde se faz política, disseram que ela acontece em todos lugares: "[...] tá em todos os aspectos da vida cotidiana e da vida dos sujeitos, [...] todas relações são permeadas de política." (PROFESSOR 2.3, 2019); “[...] até porque nada que a gente faz é neutro, num simples ponto de vista a gente já está tomando lado nas correlações de força existentes na nossa sociedade." (PROFESSORA 1.1, 2019).

As repostas dos discentes vão ao encontro dessa perspectiva, ao afirmarem que ela acontece "Em todo lugar, principalmente dentro da escola porque tem as regras, que é uma forma de política e [...] em qualquer lugar que você for com certeza vai ter um pouquinho de política ali." (ALUNA 1.2, 2019); [...] a ocupação foi uma política, a gente lutar pelo fim da reorganização escolar foi uma política, eu estar aqui falando pra você disso é uma política, eu falar pra alguém sobre o que tá acontecendo é uma política." (ALUNA 2.1, 2019). 
Com efeito, foi possível notar que os sentidos que circulam nas práticas discursivas mudaram quando as questões sinalizaram aos entrevistados a necessidade de relacionarem as ações governamentais à escola. Para eles, tais relações

[...] tendem a ser extremamente autoritárias, existe toda uma hierarquia na estrutura escolar e essa hierarquia tende a ser seguida por pressão de alguma forma, no mínimo, então tendem a ser relações autoritárias em que ora determinações do governo exercem uma pressão sobre toda comunidade escolar e muitos gestores, diretores, no caso, acabam assumindo esse papel do Estado dentro das escolas. Então, acabam agindo de forma autoritária, existem exceções, mas como o próprio nome diz são exceções à regra do que eu conheço, pelo menos, de escolas. (PROFESSOR 1.4, 2019)

Diante do exposto, identificamos que, apesar de evidenciarem as relações hierárquicas e de subordinação dentro e fora da escola, os entrevistados parecem compartilhar do nosso referencial quando afirmam, em vários momentos da entrevista, que a escola é o espaço cotidiano da política que possibilita mudanças.

Antes de abordarmos os sentidos sobre a gestão, presentes na prática discursiva dos diferentes segmentos das escolas que participaram das ocupações, cumpre registrar que nos voltamos para essas práticas discursivas por questionarmos a ideia de gestão como mediadora da política (VIEIRA, 2007) e compreendermos que as escolas produzem políticas de gestão.

Os docentes entrevistados entendem a gestão “[...] como organização de determinado contexto, num sentido amplo. Pra mim, a gestão é esse processo de organização de determinado ambiente, que contém diversos atores." (PROFESSOR 1.4, 2019); e tal organização está relacionada ao favorecimento da aprendizagem "[...] como processos de orientação e organização da escola a fim de oferecer um ambiente favorável à aprendizagem.” (PROFESSORA 1.1, 2019).

Os alunos também consideram que a gestão abrange esses processos de organização, mas diferentemente dos professores, centralizam tal sentido no papel do "gestor". Assim, para eles, a gestão é "[...] ser um líder, mas não o que manda, e sim o que gere, o que organiza, o que arruma." (ALUNO 1.4, 2019); a relação com a aprendizagem aparece novamente quando uma das alunas afirma que gestão são as “[...] atividades que eles desenvolvem pra melhorar a escola, pra melhorar o aprendizado, a forma que eles organizam a escola." (ALUNA 1.2, 2019).

Embora os alunos e a própria gestora incluam todos os integrantes da escola e comunidade no processo de gestão (conversando, querendo saber a opinião, ouvindo, organizando), o gestor ainda parece ser considerado central. A fala da gestora da Escola 1, que demostrou um posicionamento fortemente 
contrário ao movimento de ocupação realizado pelos estudantes durante a pesquisa, sugere isso. Em suas palavras, no momento da ocupação, os alunos e alguns professores não "[...] me deixavam entrar na escola, nem para fazer os pagamentos.” (GESTORA 1.1, 2019).

Um dos alunos, no entanto, visualizou a gestão para além da figura do gestor ao afirmar que durante as ocupações eles foram "bons gestores dentro da escola" (ALUNO 1.3, 2019). De forma semelhante, duas professoras pontuam que “[...] nós somos a gestão da escola” (PROFESSORA 1.2, 2019); “[...] a gestão compreende todos que estão na escola, desde os professores, todos os funcionários, até a gestão propriamente dita né, coordenação, diretora, vice." (PROFESSORA 2.4, 2019). O professor 2.3 complementa, dizendo que sua compreensão ideal de gestão é de uma "[...] gestão participativa, onde todos constroem o espaço escolar.” (PROFESSOR 2.3, 2019).

Apesar de a gestão ter sido mais relacionada ao ato de gerir, administrar e organizar, há uma forte preocupação com a formação dos estudantes e com a responsabilização de todos que fazem parte da comunidade escolar e, após as ocupações e toda mobilização gerada, tal preocupação se intensificou nas práticas dos integrantes da escola.

Quando questionados sobre as maiores potencialidades da gestão, por exemplo, os professores, complementando as respostas anteriores, dizem que é "[...] todos poderem construir um espaço" (PROFESSOR 2.3, 2019); “[...] estabelecer uma participação efetiva de todos os atores daquele espaço pra que eles se sintam parte de um todo e não espectadores (PROFESSOR 1.4); "Então, eu vejo como um potencial da escola poder unir esses diferentes agentes e oferecer a oportunidade de refletir sobre diferentes perspectivas, buscando diferentes soluções, não as mesmas soluções.” (PROFESSORA 1.1, 2019).

Uma das principais dificuldades relacionadas à gestão, mencionada pelos entrevistados, é obedecer as demandas e a burocracia vindas de fora da escola. Ou seja, para os professores, as principais dificuldades estão localizadas nos gestores “[...] que mais reproduzem as demandas do governo." (PROFESSORA 1.1, 2019). Outra docente acrescenta que:

[...] uma gestão que cumpre à risca, de forma burocrática, sem adequar à realidade, sem identificar criticamente os interesses por trás das medidas, tornase conivente com o mesmo descaso de que reclama quando culpa a secretaria da educação pelas políticas públicas adotadas. (PROFESSORA 1.3, 2019).

Como vimos anteriormente, um dos alunos considera que ele e as outras pessoas que participaram das ocupações foram bons gestores, por isso, toma como base sua experiência para dizer que a maior dificuldade de uma gestão é 
“[...] ter que lidar com muitas pessoas, [...] na ocupação a gente tinha que lidar com muitas pessoas e isso acaba gerando um certo problema por conta de muitas opiniões diferentes, pessoas diferentes.” (ALUNO 1.3, 2019). Interessante notar que tal reposta foi bastante semelhante à da profissional responsável pela gestão escolar, que elege como maior dificuldade lidar com "bastante diferença" e com o fato "[...] das pessoas não entenderem que na escola a gente tem alunos de diferentes formas [...] não dá pra você tratar todos por igual [...] achar que a sala tem que ser homogênea." (GESTORA 2.1, 2019).

Dois professores pontuam que a maior dificuldade é não compreender a gestão como democrática. Nas palavras deles, é a “[...] falta de compreensão tanto de toda a comunidade escolar, funcionários, pais, professores, de que eles, que nós somos a gestão da escola, de que nós podemos participar e temos autonomia nas decisões.” (PROFESSORA 1.2, 2019); “[...] não se compreender a gestão como algo que deva ser democrático, não ter esse olhar de que a comunidade também é importante na construção de projetos, na construção do próprio regime ali da unidade escolar, das normas, das aprendizagens que serão desenvolvidas." (PROFESSORA 2.4, 2019).

Outras dificuldades que aparecem nas entrevistas são “[...] ter uma visão de totalidade do espaço, então, identificar todos os fatores e todos os atores que acompanham aquele espaço e como organizar isso da melhor forma possível." (PROFESSOR 1.4, 2019); "[...] saber o que fazer na hora certa, com a vontade certa e o motivo certo, porque gerir só por gerir o país acaba do jeito que tá" (ALUNO 1.4, 2019)

Em linhas gerais, as falas indicam o quão complexa é a gestão, não apenas por ela mesma, mas também pelas potencialidades e dificuldades que ela encontra, tanto em lidar com as demandas exigidas, como com a multiplicidade de pessoas que a escola abrange e suas lutas por melhores condições de trabalho e aprendizado.

Ao entendermos que a democracia está aberta a novas possibilidades e não possui um único sentido (LACLAU; MOUFFE, 2015) junto à nossa proposta de mantê-la viva (WILLIAMS, 2013), buscamos ainda identificar quais são os sentidos sobre democracia que circulam nas práticas discursivas dos integrantes da escola pública que vivenciaram o movimento de ocupação.

Em termos gerais, identificamos que em várias falas a democracia se mistura com a política e com a gestão, inclusive, muitas respostas são parecidas ou iguais às das categorias analisadas anteriormente (política e gestão).

Alguns entrevistados relacionaram democracia ao coletivo - força coletiva, ou seja, como “[...] um processo contínuo de correlação de forças, onde o povo, a multidão tem que gritar mesmo pra conseguir ser ouvida e conseguir mudar 
alguma coisa, ter alguma influência nesse poder dominante." (PROFESSORA 1.1, 2019); “[...] agir em conjunto com as ações, você ouvir o outro, dar voz pro outro, atender as necessidades do outro." (ALUNA 1.2, 2019).

Dois professores entendem a democracia "[...] num sentido mais amplo de participação de todos.” (PROFESSOR 2.3, 2019); como participação ativa, ou seja:

[...] participar ativamente da política da sua cidade, da comunidade, da sua escola e essa participação precisa ser fortalecida a cada dia né, porque a partir do momento que se tem consciência dessa força democrática, do poder que tem a participação do povo nas decisões, eu acredito que as coisas se transformam e ganham vida. (PROFESSORA 2.4, 2019).

Para outros entrevistados, a democracia é entendida "[...] como uma organização política que consiga respeitar as diferenças, que consiga dar voz às diversas parcelas de uma sociedade." (PROFESSORA 1.2, 2019). E como uma forma de governo "[...] que concentra o poder político nas mãos de todas as pessoas a quem decisões públicas interessam.” (PROFESSORA 1.3, 2019), ou como “[...] um governo onde o povo é soberano.” (FUNCIONÁRIA 2.1, 2019).

Para os alunos, a democracia está relacionada com o poder de escolher “[...] o que é melhor pra você, de poder decidir o que é melhor pro seu futuro, ou pro futuro do seu país.” (ALUNO 1.3, 2019); apesar de também citar a escolha, outra aluna relaciona o poder de escolha com o voto “[...] tem a ver em relação ao voto né, que é uma coisa democrática que a gente pode escolher alguém que irá governar por nós.” (ALUNA 2.1, 2019). Outro aluno, no entanto, considera que a democracia só acontece de forma plena, “[...] através de militância mesmo, sabe, de cobrar, de participar de manifestação, greve, de tudo, só desse jeito a democracia vem plena." (ALUNO 1.1, 2019). De acordo com outro aluno, a democracia não é algo necessariamente benéfico para todos:

[...] a democracia nada mais é do que o que a maioria das pessoas querem, e não necessariamente o certo, por isso eu não acredito tanto na democracia, mas acredito que ela foi feita pra ser a melhor decisão para todos, porque é o que a maioria concorda em ser, porém, por eu não acreditar muito na essência do homem como espécie, eu acredito que democracia nada mais é do que o que a maioria deseja que seja, que aconteça, e eles decidem isso. (ALUNO 1.4, 2019).

Quando questionados sobre as potencialidades da democracia, diversas recorrências apareceram, algumas ligadas ao poder que a democracia concede ao povo, seu potencial de melhora de uma dada situação, ou até como a melhor forma de organização social de modo a possibilitar sua transformação. 
Relacionada à primeira recorrência, para os entrevistados, a potencialidade dela está situada no momento em que "[...] o povo tem soberania" (FUNCIONÁRIA 2.1, 2019) e relacionada "[...] ao poder que o povo tem de participar das decisões, participar das transformações, das mudanças necessárias na comunidade, na cidade, no próprio país e compreender que na democracia se governa junto." (PROFESSORA 2.4, 2019).

De acordo com um dos professores, embora a democracia seja considerada uma utopia, ou seja, um horizonte a ser alcançado, é a "[...] melhor forma de organização social [...] eu penso que uma sociedade que efetivamente respeite a democracia vai ser uma sociedade muito melhor do que a sociedade em que a gente vive.” (PROFESSOR 1.4, 2019). Outro docente pontua que:

[...] se for participativa, a democracia tem um poder de transformação social, uma transformação de espaços, uma transformação e um caráter pedagógico, participar das vivências da escola, ela possibilita isso, um aluno, um professor que participa desses órgãos tem uma formação política muito maior, uma formação mais coesa, mais de compreensão da totalidade do espaço que ela tá vivenciando. (PROFESSOR 2.3, 2019).

Talvez esses sentidos sejam acentuados justamente pela burocracia, pois como menciona uma professora:

[...] aquilo que limita a gestão democrática é sempre aquelas ordens, aqueles e-mails, aqueles decretos, que chegam através dos diretores, [...] enfim, que tenta amedrontar, ameaçar, tenta, suavemente, sugerir como devem ocorrer as relações dentro de uma escola, e o desafio é fazer com que essas pessoas não acreditem ou desacreditem dessas informações, é você fazer quebrar essas informações que vem que diminuam ou que façam acreditar que não deve ser de forma democrática, então é isso. (PROFESSORA 1.2. 2019).

Muitas vezes, segundo outra docente, as pessoas "[...] acatam o que lhes foi ordenado sem refletir sobre as origens e motivações das decisões." (PROFESSORA 1.3, 2019). Para outra: “[...] os limites são estabelecidos pela nossa estrutura social, porque daí interfere na possibilidade de formação dos indivíduos.” (PROFESSOR 1.4, 2019).

Em uma perspectiva diferente, os discentes afirmam não haver limites ou dificuldades na democracia. Nas palavras de uma aluna: "Eu creio que se você souber levar, você entender a necessidade do outro e saber o seu papel acho que ela não traz nenhuma dificuldade, eu acho que a única dificuldade mesmo é [...] acontecer a democracia de fato." (ALUNA 1.2, 2019). Para outro aluno, a 
dificuldade se encontra exatamente quando "[...] você deixar de exercer, quando você para de querer exercer a democracia, eu acho que esse seja o limite." (ALUNO 1.3, 2019). Na mesma linha, uma docente pontua que a maior dificuldade:

[...] está relacionada a falta de compreensão do que é a democracia, porque atualmente nós vivemos um momento em que algumas pessoas entendem a democracia como um conceito negativo, algo que atrapalha e é totalmente o contrário, graças a democracia que nós podemos sair às ruas, [...] reivindicar, [...] discordar do que os nossos governantes estão fazendo e lutar pelos nossos direitos. (PROFESSORA 2.4, 2019).

Para a profissional que atua na gestão, a maior dificuldade "é agradar a todos" (GESTORA 2.1, 2019), principalmente pela diversidade e multiplicidade de opiniões existentes. Um dos alunos dá um exemplo bastante emblemático para explicar seu ponto de vista e aprofunda a fala da profissional da gestão sobre o limite da democracia, segundo ele:

[...] se você colocar 100 pessoas numa sala e 99 delas são nazistas e um é negro, 99 concordam que aquele negro tem que morrer, a democracia seria ele morrer, mas é errado, então pra mim o limite da democracia é quando você interfere na liberdade de outro apenas porque você e uma outra grande parte de pessoas quer isso. (ALUNO 1.4, 2019).

Esse exemplo é interessante para articularmos como o pensamento de Laclau (2013, p. 191), ao pontuar que: "Um regime fascista pode absorver e articular demandas democráticas tanto quanto um regime liberal." Sendo assim, uma sociedade democrática não é aquela em que o melhor conteúdo reina sem contestação (e, portanto, seja difícil agradar a todos), mas onde sempre há possibilidade de questionamento e nada é alcançado de uma vez por todas. É justamente aqui que entra a importância de movimentos como as ocupações das escolas, nos quais há articulações e hegemonizações, os antagonismos são multiplicados e existe a possibilidade de que o espaço público seja plural e as demandas democráticas sejam outras.

\section{CONSIDERAÇÕES FINAIS}

Tivemos como objetivo principal analisar as práticas discursivas dos diferentes integrantes de duas escolas públicas da rede estadual paulista, ocupadas em 2015/2016 contra a reorganização escolar. Na análise, o cotidiano escolar foi perspectivado e considerado não como um mero implementador de políticas, mas como algo que possui uma complexidade que não pode ser desconsiderada. 
Todo o percurso das perspectivas de estudo da escola foi e é importante para as discussões atuais em torno da temática, pois o conhecimento se dá com esse movimento, ou seja, reconhecer até onde você consegue ir com determinadas perspectivas, reconhecer seus limites e buscar formulações que abarquem a complexidade e a multiplicidade que surge no cotidiano escolar e que determinada perspectiva não dá mais conta.

As ocupações são um exemplo de como o cotidiano escolaré ressignificado e modificado constantemente. Além desse movimento específico, vários outros estão acontecendo. Assim, esse tipo de estudo é importante para ressignificar a forma como olhamos para a construção do conhecimento.

Como referencial teórico-metodológico, utilizamos a teoria do discurso de Laclau e Mouffe (2015), que sustenta a impossibilidade de fechamento de sentidos e que a verdade (mesmo provisória) se encontra nos "limites", naquilo que escapa à regularidade. Levando em consideração as leituras dos referidos autores e as falas dos entrevistados, reconhecemos o movimento de ocupação das escolas como hegemônico, pois as condições para a hegemonia são justamente a presença de forças antagônicas se articulando para criar pontos nodais e significantes vazios. O momento desse vazio surge exatamente após o estabelecimento de cadeias de equivalências, como é o caso das ocupações, mas essa "imprecisão" e "vagueza" não resulta de uma situação marginal, pois estão inscritas na própria natureza do político (LACLAU; MOUFFE, 2015).

Nenhuma das demandas particulares dos entrevistados seria suficiente para ocupar as escolas, eles precisaram se articular e equivaler, não deixando suas particularidades e paixões de lado, mas articulando-se para um objetivo comum: lutar contra a reorganização escolar. Esse se tornou seu ponto nodal e seu significante vazio - não por ser um lugar impreciso, mas por ser um lugar constitutivamente irrepresentável, justamente pela enorme quantidade de particularidades que possui.

Reconhecemos as ocupações das escolas também como um movimento democrático, pois uma sociedade democrática, segundo Laclau (2011), não é aquela em que o melhor conteúdo reina sem contestação, como no caso das ocupações, mas sim aquela em que há a constante possibilidade de questionamento e nada é alcançado definitivamente. Ademais, a democracia só se torna possível se reconhecermos o valor que uma identidade deslocada possui. Concordamos com o autor quando afirma que vivemos em uma sociedade em que é cada vez mais difícil se referir a um nível primário ou único no qual se constituiria a identidade básica dos agente sociais. Tais agentes, cada vez mais, estão se tornando 
"subjetividades múltiplas" e há uma proliferação de pontos na sociedade onde serão tomadas decisões que afetarão as vidas de todos, algo que pode ser visto em várias falas dos entrevistados, parecendo já reconhecer isso.

A análise das práticas discursivas foi focalizada nas categorias: política, gestão e democracia. Em relação à política, apesar de evidenciarem as relações hierárquicas e de subordinação dentro e fora da escola, os entrevistados compartilharam do nosso referencial quando afirmaram, em vários momentos das entrevistas, que a escola é o espaço cotidiano da política que possibilita mudanças. Os funcionários, professores, alunos e gestora compreendem a política presente em todos os lugares e na constituição das próprias relações sociais, mas indicam, com clareza, o autoritarismo da política do governo direcionada à escola.

Sobre a gestão, diferentemente dos professores que dizem que esta é feita por todos que estão na escola e em todos os lugares, os alunos e a gestora, embora incluam todos os integrantes da escola e da comunidade no processo de gestão, ainda consideram a figura do gestor como central. Nas falas de todos os entrevistados, a política se integra à gestão, não sendo possível precisar os limites de uma e de outra, constatação que também se aproxima de nossa perspectiva analítica. De modo geral, identificamos que a democracia se mistura com a política e com a gestão, inclusive muitas vezes podemos ver respostas parecidas ou iguais às categorias analisadas anteriormente. Há uma defesa da democracia como a forma mais adequada de se fazer política de gestão e, portanto, não como algo utópico, mas possível e vivenciado, mesmo com o enfrentamento de todas as dificuldades.

Finalmente, mediante a análise efetuada, podemos dizer que a experiência nas ocupações teve grande importância na ressignificação das categorias política, gestão e democracia e também na ressignificação da escola. Foi possível notar isso por meio do reconhecimento dos próprios entrevistados, principalmente os alunos, que consideram que apenas conseguiram responder por terem participado do movimento e vivido isso na prática. A escola é permeada por relações políticas e democráticas, e quanto mais elas são potencializadas, por meio do envolvimento de seus integrantes, em movimentos como esse, maiores são as possibilidades de articulações e hegemonizações na sociedade. O percurso nos mostra as possibilidades de a teoria do discurso de Laclau e Mouffe (2015) contribuirem com a análise da gestão escolar. 


\section{REFERÊNCIAS}

ABDIAN, G. Z.; ANDRADE, E.; PARRO, A. L. G. Sentidos de política e/de gestão nas pesquisas sobre a escola. Educação e Pesquisa, São Paulo, v. 43, n. 3, p. 727-742, jul./set. 2017.

ABDIAN, G. Z. Revezamento teoria e prática na análise da escola pública democrática. Educar em Revista, Curitiba, Brasil, v. 34, n. 68, p. 107-122, mar./ abr. 2018.

ABDIAN, G. Z. O cotidiano como princípio educativo nas pesquisas em Educação. Acta Sci. Educ., v. 42, p. 2-11, 2020.

CANÁRIO, R. A escola tem futuro? Das promessas às incertezas. Porto Alegre: Artmed, 2006.

CARVALHO, V. I. Gestão democrática: práticas discursivas dos integrantes de escolas públicas estaduais paulistas ocupadas em 2015/2016. 135 p. Dissertação (Mestrado em Educação) - Universidade Estadual Paulista (Unesp), Faculdade de Filosofia e Ciências, 2020.

GALLO, S.; FIGUEIREDO, G. M. Entre maioridade e menoridade: as regiões de fronteiras no cotidiano escolar. Aprender: Cadernos de Filosofia e Psicologia da Educação. Vitória da Conquista, ano IX, n. 14, p. 25-51, 2015.

LACLAU, E. A razão populista. São Paulo: Três Estrelas, 2013.

LACLAU, E.; MOUFFE, C. Hegemonia e estratégia socialista: por uma política democrática radical. Tradução Joanildo A. Burity, Josias de Paula Jr. E Aécio Amaral. São Paulo: Intermeios; Brasília: CNPq, 2015. (Coleção Contrassensos).

MAIA, G. Z. A. As publicações da ANPAE e a trajetória do conhecimento em Administração da Educação no Brasil. 2004. Tese (Doutorado em Educação) - Faculdade de Filosofia e Ciências, Universidade Estadual Paulista, Marília, 2004. 196 f.

MOUFFE, C. Entorno a lo político. Buenos Aires: FCE, 2011. 
RUSSO, D. A.; MAIA, G. Z. A. A escola como objeto de estudo da ciência da educação no Brasil (1990-2005). RBPAE, v. 25, n. 3, p. 523-541, set./dez. 2009.

SOUZA, Â. R. de. Perfil da gestão escolar no Brasil. 2006. Tese (Doutorado em Educação) - Pontifícia Universidade Católica de São Paulo, São Paulo, 2006.

VIEIRA, S. L. Política(s) e gestão da educação básica: revisitando conceitos simples. RBPAE, v. 23, n. 1, p. 53-69, 2006.

WILLIAMS, J. Pós-Estruturalismo. 2. ed. Petrópolis: Vozes, 2013.

\section{Graziela Zambão Abdian}

Possui graduação em Pedagogia pela Universidade Estadual Paulista Júlio de Mesquita Filho (1995), mestrado e doutorado em Educação pela Universidade Estadual Paulista Júlio de Mesquita Filho (2000; 2004) e pós-doutorado, pelo Programa PDJ do CNPq, na Universidade do Vale do Rio dos Sinos. Professora assistente doutora do Departamento de Administração e Supervisão Escolar e do Programa de Pós-Graduação em Educação da Universidade Estadual Paulista Júlio de Mesquita Filho (Marília/SP). Coordenadora do Programa de Pós-graduação em Educação da FFC/UNESP/Marília (2017-2021). Tem experiência na área de Educação, atuando principalmente nos seguintes temas: administração/gestão da educação, administração/gestão escolar, política educacional. E-mail: graziela.maia@gmail.com

\section{Viviane Izaías de Carvalho}

Possui graduação em Pedagogia pela Universidade Estadual Paulista Júlio de Mesquita Filho (2017) e Mestrado em Educação pela Universidade Estadual Paulista Júlio de Mesquita Filho (2020). Tem experiência na área de Educação, com ênfase em Administração Educacional. Atuando principalmente nos seguintes temas: Educação, Política e Gestão democrática, Escolas estaduais paulistas, Ocupação de escolas, Teoria do Discurso.

viviane_izaias@hotmail.com 


\section{Viviani Fernanda Hojas}

Doutora e Mestre em Educação pelo Programa de Pós-Graduação em Educação da Universidade Estadual Paulista (UNESP/Marília). Graduada em Pedagogia pela Universidade Estadual Paulista (UNESP/Marília). Professora Contratada em Regime Especial (CRES) pela Universidade Estadual do Norte do Paraná (UENP/Campus de Jacarezinho) e Professora Colaboradora do Programa de Pós-Graduação em Educação da Universidade Federal do Acre (PPGE/UFAC). Tem experiência docente na Educação Básica e Superior e atua principalmente nos seguintes temas de pesquisa: políticas educacionais, gestão da educação, sistemas de avaliação e formação de profissionais da educação. E-mail: vihojas@ hotmail.com 